\title{
Screening for Cognitive Impairment: A Triage for Outpatient Care
}

\author{
Ulrike Beinhoff ${ }^{a, c}$ Verena Hilbert ${ }^{c}$ Daniel Bittner ${ }^{c}$ Georg Grön ${ }^{b}$ \\ Matthias W. Riepe ${ }^{a, c}$ \\ ${ }^{a}$ Department of Psychiatry, Charité Medical University, Berlin, and Departments of ${ }^{b}$ Psychiatry, and ${ }^{\mathrm{c}}$ Neurology, \\ University of UIm, UIm, Germany
}

\section{Key Words}

Alzheimer's disease $\cdot$ Major depression $\cdot$ Mild cognitive impairment $\cdot$ Neuropsychological investigations .

Screening tests $\cdot$ Cognitive impairment

\begin{abstract}
The current increase in aged individuals in number and proportion of the general population warrants dependable strategies to improve early detection of cognitive impairment. It was the goal of the present study to develop a triage for bedside testing and outpatient services. In a prospective clinical cohort study at the outpatient Memory Clinic, University of Ulm, Germany, 232 subjects were diagnosed with Alzheimer's disease [AD; NINCDS-ADRDA criteria; $n=66$; age $65.9 \pm 7.3$ years (mean $\pm \mathrm{SD}$ ); Mini Mental State Examination (MMSE) score $23.4 \pm 4.1$ ], mild cognitive impairment (MCl; criteria of Petersen et al.; $n=48$; age $66.4 \pm 7.1$ years; MMSE score $28.3 \pm 1.5$ ), and major depressive disorder (DSMIV criteria; $\mathrm{n}=61$; age $63.4 \pm 8.0$ years; MMSE score 28.6 $\pm 1.6)$. Diagnosis was secured with extensive neuropsychological, clinical, radiological, and laboratory investigations. Six brief screening tests including the Memory Impairment Screen (MIS), Letter Sorting Test (LST), Verbal Fluency (VF), and Clock Drawing Test (CDT) were assessed independently from the diagnostic procedure. We compared single items and composite scores. LST yielded a diagnostic accuracy of 0.81 and 0.62 for $A D$ and
\end{abstract}

$\mathrm{MCl}$ patients versus controls, respectively. With the MIS, diagnostic accuracy was 0.89 and 0.71 , respectively. With a combination of LST, MIS, VF, and CDT, a sensitivity for $A D$ and $\mathrm{MCl}$ patients of 1.00 and 0.83 was achieved. Thus, single-item screening (e.g. LST, VF) taking little more than $1 \mathrm{~min}$ and suitable for bedside testing or brief screening in the general practitioner's office yields diagnostic accuracy comparable to standard laboratory tests for other diseases. A composite of screening tests suitable for application in general outpatient care in neurological and psychiatric services reliably detects patients with $A D$ and $\mathrm{MCl}$.

Copyright (C) 2005 S. Karger AG, Basel

\section{Introduction}

With the increase in life span, the absolute number and proportion of aged individuals increase at present. As a consequence, age-related cognitive disorders, such as neurodegenerative dementia, will become even more prevalent over the next years. Considering that cognitive impairment results in increased use of health services and increased mortality [1] and taking into account that new treatment options emerge, it is warranted that screening and diagnostic tools are improved.

At present, dementia afflicts up to $30 \%$ of the general population depending on age and diagnostic criteria $[2,3]$. Alzheimer's disease (AD) is the most common

\section{KARGER \\ Fax +4161306 1234 E-Mail karger@karger.ch} www.karger.com

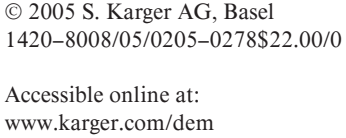

www.karger.com/dem

Prof. Matthias W. Riepe, MD

Department of Psychiatry, Mental Health and Old Age Psychiatry

Eschenallee 3

DE-14050 Berlin (Germany)

Tel. +49 308445 8253, Fax +49 308445 8255, E-Mail matthias.riepe@charite.de 
cause of dementia and may be preceded by amnestic mild cognitive impairment (MCI) [4], a condition with selective impairment of memory and an increased risk for developing manifest Alzheimer's dementia. MCI is prevalent in endemic proportions as well [5], as is major depressive disorder (MD) [6]. Patients with MD also frequently complain about memory impairment [7, 8], sometimes culminating in a syndrome named 'depressive pseudodementia' [9, 10]. Vice versa, depressive symptoms are frequently part of very early AD [10-13]. In general, cognitive impairment frequently remains unrecognized even by medical personnel [14]. A recent study estimated that only $25 \%$ of patients with MCI or $\mathrm{AD}$ are recognized in general practice [15]. It is established that screening with formalized screening tests is superior to general clinical judgement [16]. However, the consistence with rigorous diagnostic procedures comprising extensive neuropsychological testing is far from clear.

The defining criterion of amnestic MCI is impairment of episodic memory, which indicates medial temporal lobe dysfunction in these subjects [4]. Similarly, the medial temporal lobe is affected at onset of $\mathrm{AD}$ [17], resulting in episodic memory deficit as the hallmark of early $\mathrm{AD}$ [18]. With sophisticated methods such as functional magnetic resonance imaging, impairment of the hippocampal function may be portrayed objectively [19]. Concerning memory, even a continuum from health to disease can be shown [20]. With progressing disease, AD spreads out to subsequently affect the parietal and frontal lobe which may also be portrayed objectively with elaborated and expensive methods [21].

The parietal cortex mediates functions such as spatial orientation and visuospatial functions [22, 23], the frontal cortex executive functions, planning, attention, and working memory [24-26]. Spread of AD beyond the temporal lobe is thus mirrored in functional terms by accruing deficits of spatial orientation, attention and executive functions as well as working memory and language [18] beyond initial temporal lobe type memory deficits. In contrast to $\mathrm{MCI}$ and $\mathrm{AD}$, cognitive deficits in subjects with MD, even with mild disease, result mainly from impaired frontal cortex function [27-29].

The temporal pattern of functional impairment in $\mathrm{AD}$ has even been observed in cognitive screening tests such as the Mini Mental State Examination (MMSE) [30]. Thus, screening instruments need to account for this temporal pattern and should address medial temporal lobe function when aiming at screening for subjects with MCI or mild AD while including other cognitive domains me- diated by the parietal and frontal cortex when screening for later stages of the disease.

At present, several screening procedures have been proposed, e.g. the 7-Minute Screen [31], the Hopkins Verbal Learning Test [32], the Memory Impairment Screen (MIS) [33, 34], the Rapid Dementia Screening Test [35], the DemTect [36], and the Short Cognitive Evaluation Battery [37]. Even the cognitive part of the Alzheimer's Disease Assessment Scale (ADAScog) has been proposed as a screening instrument [38]. However, in general, these screening tests do not account for the temporal development of $\mathrm{AD}$ and mingle the results of several cognitive functions into one composite score. Moreover, most of the screening procedures reported thus far do not include patients with MD. In addition, few tests are easy enough to administer, short enough to be used in general practice, or lack diagnostic accuracy. Also, most of the screening tests currently in use do not account for patients with physical handicaps, e.g. impaired motor functions or visual or hearing impairment.

Although the MMSE was developed as a brief dementia screening procedure [39], it nowadays is not used as a screening procedure any more but for assessment of dementia severity. The MMSE was reported not to be superior to age alone in predicting $\mathrm{AD}$ [40]. Nevertheless, even longer tests of cognitive function, such as the Structured Interview for the Diagnosis of Dementia of the Alzheimer Type, Multi-Infarct Dementia and Dementias of Other Etiologies (SIDAM) or the ADAScog, may not necessarily be superior to the MMSE [41, 42]. Thus, more reliable tests and a comparison of screening tests are warranted.

A common problem of everyday clinical work is the time constraint. It was the primary goal of this study to develop a triage of screening instruments for bedside testing (time consumption less than a minute) and screening in general medicine and neurology/psychiatry services (time consumption less than $10 \mathrm{~min}$ ) that has been substantiated by rigorously examining not only patients but also normal subjects. For this, several brief screening tests have been assessed individually as well as a combination thereof in patients with $\mathrm{AD}, \mathrm{MCI}$ and MD.

\section{Methods}

The study was performed according to institutional guidelines and the principles outlined in the Declaration of Helsinki.

Patients

Two hundred and thirty-two subjects seeking first time advice on subjective memory complaints in the outpatient Memory Clinic 
Table 1. Descriptive data of the study population

\begin{tabular}{lllll}
\hline & AD & MCI & MD & HC \\
\hline Patients & 66 & 48 & 61 & 57 \\
Age & $65.9 \pm 7.3$ & $66.4 \pm 7.1$ & $63.4 \pm 8.0$ & $63.5 \pm 7.5$ \\
Female/male & $34 / 32$ & $15 / 33$ & $36 / 25$ & $27 / 30$ \\
MMSE score & $23.4 \pm 4.1$ & $28.3 \pm 1.5$ & $28.6 \pm 1.6$ & $29.4 \pm 0.9$ \\
Education & $1.56 \pm 0.85$ & $1.87 \pm 0.94$ & $1.56 \pm 0.73$ & $1.98 \pm 0.87$ \\
\hline
\end{tabular}

Education: 1 = up to 10 years of education equivalent to the degrees of the German 'Hauptschule' or 'Realschule'; 2 = more than 10 and up to 13 years of education equivalent to the German 'Gymnasium', or 3 = university degree.

of the University of Ulm, Germany, were investigated with several screening tests and extensive neuropsychological, clinical, radiological, and laboratory investigations. AD was diagnosed according to the NINCDS-ADRDA criteria [43], MCI according to the criteria of Petersen et al. [4], and MD according to DSM-IV criteria. Subjects were considered as healthy controls (HC) only when findings on extensive neuropsychological, clinical, radiological, and laboratory investigations were normal and medical history was free from any neurological or psychiatric disease. The demographic characteristics, education, and severity of the dementia syndrome assessed by the MMSE are given in table 1. Education was assessed on a three-level scale ( $1=$ up to 10 years of education equivalent to the degrees of the German 'Hauptschule' or 'Realschule'; 2 = more than 10 and up to 13 years of education equivalent to the German 'Gymnasium', or 3 = university degree). No difference in age and education was found between these groups $(\mathrm{p}>0.05)$. AD patients had significantly lower scores on the MMSE than other subjects (MCI, $\mathrm{MD}$, and $\mathrm{HC} ; \mathrm{p}=0.001)$. There were no significant differences between MCI, MD, and HC subjects ( $p>0.05)$.

\section{Screening Items}

Six screening tasks already reported in the literature [44, 45] and in part used previously to screen for cognitive impairment in patients with acute stroke [46] were investigated. All of these tasks are quick to administer, easy to score, and cover the main cognitive domains commonly impaired in dementia, i.e. immediate and delayed recall of verbal information, working memory, visuoconstructive abilities, orientation, naming objects, and cognitive flexibility.

Letter Sorting Test. Working memory and concentration were assessed with the Letter Sorting Test (LST) as previously reported [45]. Subjects are asked to spell a 5-digit word forwards, backwards, and in alphabetical order. In the present study, patients had to spell the German word 'sanft'. Time consumption for this test was less than $1 \mathrm{~min}$. Scoring was according to the original report giving 1 point each for spelling forwards, backwards and in alphabetical order.

Orientation. Orientation was assessed with the subscale orientation of the ADAScog [47]. Subjects are asked 8 questions regarding time, place, and situation. Time consumption for this test was about $1 \mathrm{~min}$. Each correctly answered item was scored with 1 point.
Memory Impairment Screen. Memory was assessed with the previously published MIS [44]. With this test, the delayed free and cued recall of four items is tested. Scoring was according to the original report, i.e. 2 points for each word recalled spontaneously and 1 point for each word reported on providing the semantic category. Application and recall of the words took about $2 \mathrm{~min}$, plus additional 2 min for the delay period.

Boston Naming Test. Naming deficits were assessed with the Boston Naming Test (BNT) requiring subjects to name 15 line drawings [48], taking approximately 1-2 min. Each correctly named picture was scored with 1 point.

Verbal Fluency. A test of verbal fluency (VF) was applied to measure cognitive flexibility and speed of access to semantic information [48]. Subjects are asked to generate as many words as possible of a specific category (in this study: animals) within a given period of time (in this study: $60 \mathrm{~s}$ ).

Clock Drawing Test. In the clock drawing test (CDT), patients are given a sheet of paper with a circle on it. They are then asked to follow a two-step instruction: 'This is a clock. Please draw all the numbers on it and the time 'ten past eleven'. This test was originally developed to assess visuoconstructional abilities, but it also requires language comprehension, numerical knowledge, strategy planning, and memory. The CDT was graded with 1-6 according to the method suggested by Shulman [49]. On average, it took about 1-2 min to complete the test.

\section{Statistics}

All statistical analyses for the investigation of group differences were carried out using the statistics program SPSS (SPSS 11.0 for Windows, Chicago, Ill., USA, 2001). A 1-way ANOVA with the factor 'study group' (AD, MCI, MD, HC) was run to test for group differences. For post hoc comparisons, the Tukey test was used. Sensitivity, specificity, and diagnostic accuracy were calculated for each screening item and combinations thereof.

For these composite scores, scores from several tests were combined with a Boolean 'AND', such that performance was considered normal only when scores in each test were above the given threshold. The rationale for this was to give credit to each single cognitive domain and that normal subjects should exceed a given cutoff score in each and every neuropsychological domain.

\section{Results}

\section{Single Screening Items}

Means and standard deviations of all measures are given in table 2. For each screening item, the global ANOVA including all four study groups was significant at $\mathrm{p}<$ 0.001. Post hoc analyses are discussed below. Table 3 presents cutoff scores of all screening items with their sensitivity and specificity values for each study group.

Letter Sorting Test. Post hoc analysis revealed significant differences for all groups ( $\mathrm{p} \leq 0.02)$, except for MCI versus $\mathrm{MD}$ and $\mathrm{HC}(\mathrm{p} \geq 0.5)$. With a cutoff score $<3$, a sensitivity of $80 \%$ and a specificity of $84 \%$ was achieved for the distinction of AD and controls. Total diagnostic 
Table 2. Raw scores of single screening items

\begin{tabular}{lrrrr}
\hline & $\begin{array}{l}\text { AD } \\
(\mathrm{n}=66)\end{array}$ & $\begin{array}{l}\text { MCI } \\
(\mathrm{n}=48)\end{array}$ & $\begin{array}{l}\text { MD } \\
(\mathrm{n}=61)\end{array}$ & \multicolumn{1}{l}{$\begin{array}{l}\mathrm{HC} \\
(\mathrm{n}=57)\end{array}$} \\
\hline LST & $1.6(0.9)$ & $2.6(0.6)$ & $2.4(0.8)$ & $2.8(0.5)$ \\
OR & $6.6(1.5)$ & $7.9(0.4)$ & $7.8(0.4)$ & $7.9(0.2)$ \\
MIS & $2.2(2.3)$ & $5.3(2.2)$ & $6.0(2.0)$ & $7.1(1.1)$ \\
BNT & $12.7(2.4)$ & $14.1(1.2)$ & $14.3(1.2)$ & $14.7(0.7)$ \\
VF & $13.6(4.9)$ & $18.7(5.1)$ & $18.9(6.3)$ & $23.7(4.5)$ \\
CDT & $2.9(1.1)$ & $1.5(0.7)$ & $1.9(1.0)$ & $1.3(0.6)$ \\
\hline
\end{tabular}

$\mathrm{OR}=\mathrm{ADAScog}$ subscale orientation. Figures are means, with standard deviations in parentheses.

Table 3. Sensitivity and specificity values of each screening item in all groups

\begin{tabular}{|c|c|c|c|c|c|}
\hline \multirow[t]{2}{*}{ Cutoff scores } & \multicolumn{3}{|c|}{ Sensitivity } & \multicolumn{2}{|c|}{ Specificity } \\
\hline & $\mathrm{AD}$ & $\mathrm{MCI}$ & $\mathrm{MD}+$ & MD- & $\mathrm{HC}$ \\
\hline \multicolumn{6}{|l|}{ LST } \\
\hline 3 & 0.8 & 0.35 & 0.43 & 0.57 & 0.84 \\
\hline 2 & 0.44 & 0.04 & 0.13 & 0.87 & 0.96 \\
\hline 1 & 0.12 & 0.00 & 0.03 & 0.97 & 1.00 \\
\hline \multicolumn{6}{|l|}{ OR } \\
\hline 8 & 0.65 & 0.08 & 0.15 & 0.85 & 0.95 \\
\hline 7 & 0.39 & 0.02 & 0.02 & 0.98 & 1.00 \\
\hline \multicolumn{6}{|l|}{ MIS } \\
\hline 8 & 0.98 & 0.79 & 0.72 & 0.28 & 0.46 \\
\hline 7 & 0.92 & 0.65 & 0.54 & 0.46 & 0.75 \\
\hline 6 & 0.88 & 0.50 & 0.33 & 0.67 & 0.89 \\
\hline 5 & 0.82 & 0.35 & 0.21 & 0.79 & 0.98 \\
\hline \multicolumn{6}{|l|}{$\mathrm{BNT}$} \\
\hline 15 & 0.71 & 0.50 & 0.38 & 0.62 & 0.74 \\
\hline 14 & 0.55 & 0.25 & 0.18 & 0.82 & 0.93 \\
\hline 13 & 0.39 & 0.08 & 0.10 & 0.90 & 0.98 \\
\hline \multicolumn{6}{|l|}{ VF } \\
\hline 24 & 0.98 & 0.81 & 0.77 & 0.23 & 0.49 \\
\hline 23 & 0.97 & 0.79 & 0.74 & 0.26 & 0.67 \\
\hline 22 & 0.95 & 0.75 & 0.62 & 0.38 & 0.72 \\
\hline 21 & 0.94 & 0.73 & 0.54 & 0.46 & 0.81 \\
\hline 20 & 0.94 & 0.67 & 0.49 & 0.51 & 0.86 \\
\hline 19 & 0.85 & 0.56 & 0.46 & 0.54 & 0.89 \\
\hline \multicolumn{6}{|l|}{ CDT } \\
\hline 1 & 0.86 & 0.40 & 0.61 & 0.39 & 0.60 \\
\hline 2 & 0.71 & 0.10 & 0.21 & 0.79 & 0.95 \\
\hline 3 & 0.29 & 0.02 & 0.05 & 0.95 & 1.00 \\
\hline
\end{tabular}

Subjects scoring below the threshold are diagnosed as diseased. Sensitivity $=$ Correct detection of cognitively impaired; specificity $=$ correct detection of cognitively normal; $\mathrm{MD}+=$ sensitivity for MD diagnosed as diseased; MD- = specificity for MD diagnosed as cognitively normal; OR = ADAScog subscale orientation. accuracy was 0.82 for the comparison of $\mathrm{AD}$ patients versus $\mathrm{HC}$ and 0.62 for the comparison of MCI subjects versus HC. However, the LST was not effectively classifying MCI subjects (sensitivity: 35\%) and MD patients (specificity: $57 \%)$.

Orientation. Post hoc analysis revealed significant differences only between $\mathrm{AD}$ and other groups (MCI, MD, and $\mathrm{HC} ; \mathrm{p}<0.001)$. Whereas this screening measure provides high specificity scores $(0.95-1.00)$, sensitivities are moderate for $\mathrm{AD}$ patients $(0.65)$ and very low for $\mathrm{MCI}$ (0.08). With a cutoff $<8$, total diagnostic accuracy was 0.79 for the comparison of AD patients versus controls and 0.55 for the comparison of MCI subjects versus controls. Orientation seems to be only moderately useful for testing patients with $\mathrm{AD}$, but not for differentiating $\mathrm{MCI}$ subjects from $\mathrm{HC}$.

Memory Impairment Screen. Post hoc analysis revealed significant differences between all groups $(\mathrm{p} \leq 0.012)$. MCI subjects and MD patients were indistinguishable on this measure $(\mathrm{p} \geq 0.5)$. With a cutoff score $<5$, sensitivity (0.82) and specificity (0.98) for diagnosing AD patients was satisfying. Seventy-nine percent of MD patients were classified as normal. For a cutoff score $<6$, total diagnostic accuracy was 0.89 for the comparison of AD patients versus $\mathrm{HC}$ and 0.71 for the comparison of MCI subjects versus HC. This test can also achieve to detect the majority of patients with $\mathrm{AD}(98 \%)$ and MCI $(79 \%)$ with a cutoff score $<8$, however, at the expense of a high rate of false positives (54\%). Taken together, this screening measure provides a good discrimination between $\mathrm{AD}$ patients and $\mathrm{HC}$ and a fair distinction of subjects with MD. It was not sensitive enough in detecting MCI patients among MD patients without cognitive decline.

Boston Naming Test. On this measure, the AD group performed significantly poorer than all the other groups ( $\mathrm{p} \leq$ 0.001). MCI subjects, patients with MD and HC showed no significant differences. The highest sensitivities for $\mathrm{AD}(0.71)$ and $\mathrm{MCI}(0.50)$ patients are achieved at a cutoff score of $<15$ with a specificity of 0.74 . Total diagnostic accuracy was 0.74 for the comparison of $\mathrm{AD}$ patients versus $\mathrm{HC}$ and 0.65 for the comparison of $\mathrm{MCI}$ subjects versus HC. A single naming test seems to be only moderately useful for testing patients with $\mathrm{AD}$, but not for differentiating MCI subjects from HC.

Verbal Fluency. Post hoc analysis revealed significant group differences between all groups $(\mathrm{p}<0.001)$, except for MCI subjects and MD patients $(p=0.996)$. With a cutoff score $<20$, VF shows a good discrimination between AD patients (sensitivity 94\%) and HC (specificity $86 \%$ ). Total diagnostic accuracy was 0.90 for the com- 
Table 4. Sensitivity and specificity values for composite scores

\begin{tabular}{|c|c|c|c|c|c|c|c|c|c|c|}
\hline \multicolumn{6}{|c|}{ Cutoff values for test combinations } & \multicolumn{3}{|c|}{ Sensitivity } & \multicolumn{2}{|c|}{ Specificity } \\
\hline LST & OR & MIS & VF & CDT & BNT & $\mathrm{AD}$ & MCI & $\mathrm{MD}+$ & MD- & $\mathrm{HC}$ \\
\hline- & - & $<5$ & $<20$ & - & - & 0.98 & 0.75 & 0.54 & 0.46 & 0.84 \\
\hline- & $<7$ & $<5$ & $<20$ & - & - & 0.98 & 0.75 & 0.56 & 0.44 & 0.84 \\
\hline- & - & $<5$ & $<20$ & - & $<14$ & 0.98 & 0.77 & 0.57 & 0.43 & 0.81 \\
\hline$<3$ & - & $<5$ & $<20$ & $>2$ & - & 1.00 & 0.83 & 0.72 & 0.28 & 0.74 \\
\hline- & $<7$ & $<5$ & $<13$ & - & - & 0.85 & 0.42 & 0.28 & 0.72 & 0.98 \\
\hline- & $<7$ & $<6$ & $<20$ & - & - & 0.98 & 0.81 & 0.56 & 0.44 & 0.77 \\
\hline- & $<7$ & $<6$ & $<19$ & - & - & 0.98 & 0.79 & 0.54 & 0.46 & 0.81 \\
\hline$<3$ & $<7$ & $<5$ & $<19$ & - & - & 0.98 & 0.77 & 0.66 & 0.34 & 0.79 \\
\hline
\end{tabular}

Subjects scoring below the threshold in any of the tests named in each row are diagnosed as diseased. '-' = This test was not considered in the composite score; MD+ = sensitivity for MD diagnosed as diseased; MD- = specificity for MD diagnosed as cognitively normal; OR = ADAScog subscale orientation. parison of $\mathrm{AD}$ patients versus $\mathrm{HC}$ and 0.77 for the comparison of MCI subjects versus HC. It is less sensitive for MCI subjects and less specific for MD patients (tables 2, 3 ) due to a great overlap between both groups. If the cutoff is set higher, e.g. $<24$, the majority of $\mathrm{AD}$ patients $(98 \%)$ and MCI subjects (81\%) are detected, but at the expense of low specificity (49\%).

Clock Drawing Test. Post hoc analysis revealed significant differences for all groups ( $p \leq 0.006)$, except for $\mathrm{MCI}$ versus $\mathrm{MD}$ and $\mathrm{MCI}$ versus $\mathrm{HC}(\mathrm{p} \geq 0.5)$. With a cutoff point of $>1,86 \%$ of AD patients but only $40 \%$ of MCI patients were detected. Total diagnostic accuracy was 0.81 for the comparison of $\mathrm{AD}$ patients versus $\mathrm{HC}$ and 0.57 for the comparison of MCI subjects versus HC. This instrument seems only suitable for the detection of AD but not for MCI.

\section{Combined Screening Items}

A combination of various screening items was investigated, in order to improve classification values according to the clinical application. Performance was considered normal only when scores in each test were above the given threshold. For example, in the first row (table 4), only MIS and VF are combined (MIS $<5$ and $\mathrm{VF}<20$ ) into a composite score. A result such as MIS $=5$ and $\mathrm{VF}=20$ was considered 'normal', whereas MIS $=4$ and $\mathrm{VF}=20$ was considered as indicating disease (table 4).

Detection of $A D$. The combination of the best single tests (MIS $<5$ or $\mathrm{VF}<20$ ) provides both, high sensitivity for $\mathrm{AD}(98 \%)$ and specificity for $\mathrm{HC}(84 \%)$. An additional inclusion of orientation (orientation $<7$ ) or BNT (BNT
$<14)$ does not change sensitivity and specificity values. In order to further improve sensitivity, the CDT and LST can be included (LST $<3$, MIS $<5, \mathrm{VF}<20$, or CDT $>2$ ), which renders a detection rate of $100 \%$, but at the expense of specificity for $\mathrm{HC}(74 \%)$.

Detection of $M C I$. The same combination as suggested above (MIS $<5$ or VF $<20$ ) detects $75 \%$ of MCI subjects with a specificity of $84 \%$. In order to improve sensitivity for MCI $(83 \%)$, the combination LST $<3$, MIS $<5$, VF $<20$, or CDT $>2$ can be chosen, but at the expense of specificity for $\mathrm{HC}$, which decreases to $74 \%$.

Detection of $M D$. For a differential diagnosis, $\mathrm{AD}$ and MCI patients have to be separated from MD patients. With the combination of items suggested before (MIS $<5$ or VF $<20$ ), every second MD patient is classified as 'patient with cognitive decline' (MD+). An increase in specificity for depression (MD-) above 70\% leads to a decrease in sensitivity for $\mathrm{AD}(85 \%)$ and $\mathrm{MCI}(42 \%)$ patients. There is a great overlap between groups of $\mathrm{AD}$, $\mathrm{MCI}$ and MD, making a differential diagnosis difficult even with composite scores.

\section{Discussion}

Treatment of AD has been shown to be cost effective when initiated early and at optimal dose and to delay the natural course of the disease [50,51]. Due to the increased proportion and absolute number of patients with dementia, effective screening instruments are required and will in the long run help to decrease health care costs. Due to 
the relative small number of patients seen by physicians specialized in the diagnosis of dementia, an effective triage needs to be developed that allows general practitioners, physicians of all specialties, or even nurse practitioners to screen for dementia. In order to really be used in general practice, these tests need to be easy to administer, easy to score, and dependable. Some of the screening tests currently in use may not be administered to patients with physical handicaps, e.g. impaired motor functions or visual or hearing impairment. The tests presented here do not require sophisticated motor skills and can be performed even with impairment of hearing or sight. It was the primary goal of this study to develop a triage of screening instruments. For this, several brief screening tests have been assessed individually as well as in combination. With an appropriate cutoff, all of the screening items investigated show a fair sensitivity for patients with $\mathrm{AD}$.

\section{Evaluation of Single-Item Screening Measures}

LST [45] is the fastest and easiest test to screen for cognitive impairment. It is performed in about $1 \mathrm{~min}$ but nevertheless offers a diagnostic accuracy of about 0.8 for subjects with AD. Not surprisingly, this test is not sensitive enough to detect subjects with MCI or discern between MCI subjects and patients with MD. In functional terms, it requires the online manipulation of verbal material and thus most likely requires working memory functions mediated predominantly by the frontal cortex. Given that working memory is not the earliest impairment in subjects with $\mathrm{AD}$ [18], it is not surprising that it is less sensitive than other single-item tests. Nevertheless due to its simplicity, its briefness, and lack of requirement of even pencil and paper, it may be of great value to screen for cognitive decline under conditions of narrow time constraints such as bedside or on rounds.

The results of VF and MIS were almost alike and showed fair sensitivity to detect AD patients and MCI subjects against $\mathrm{HC}$ as also reported in previous studies [52]. Good results in these tests are not surprising given the nature of the tasks. The MIS is an episodic memory task with a delayed recall condition and thus relies on intact function of the medial temporal lobe [18]. While the MIS was reported to be superior to the category fluency in a previous study [34], we find the results to be alike in the present study. It may be speculated whether this discordance results from the conditions under which the tests were administered. In the former report, administration was via the telephone and this may have hampered attention known to strongly influence results of fluency tasks. The MIS shows a good discriminative valid- ity for patients with $\mathrm{AD}$ and MCI. About $80 \%$ were correctly identified in each group. Although MD patients are known to be vulnerable to free recall memory tasks, recognition memory and cued recall are comparatively better preserved. In this test, category cues are used, in order to maximize retrieval of not freely generated words. In comparison to $\mathrm{AD}$ patients, MD patients are able to benefit from these cues and improve overall recall.

A recent work clearly demonstrated the requirement of the medial temporal lobe for verbal fluency performance [53]. This further indicates that tests that rely on integrity of the medial temporal lobe are suited best to recognize subjects with amnestic MCI and very early AD. However, these tests also fail to discern MCI subjects from patients with MD and a large part of MD patients show subnormal performance in the category fluency. This is likely to result from the requirement of frontal networks to solve the fluency task $[54,55]$ and the hypofrontality associated with MD [27-29]. It appears that in comparison the MIS more selectively relies on mid-temporal structures and allows better discernment of dementia patients from MD patients.

In general practice, the CDT is in wide use and has been shown to have a sensitivity of about $70-75 \%$ and a specificity of about $65-79 \%$ [56], which is comparable to the present study. However, its practicality is limited especially in subjects with physical handicaps and the results of the present study show that other single-item screening tests give better results. Especially for screening in situations with only slightly affected individuals, the CDT is not sufficient [57]. This is in accordance with the correlation of CDT results with left posterior temporal function being one of the regions $\mathrm{AD}$ spreads out to but does not begin in [58].

In primary care settings or bedside facing subjects not complaining of cognitive deficits themselves, it may thus be appropriate to screen with any one of these tests that show a fair sensitivity and specificity and are not costly but nevertheless effective. These tests may also be assessed on rounds and on general wards and may help to document which of the patients require further diagnostic attention. This may also improve diagnosis and treatment of any other illness even beyond a possible dementing disease.

\section{Evaluation of Composite Screening Measures}

For outpatient services and in situations with more specific demand for assessment of cognitive performance, it is necessary to use a test combination which provides better classification than single-item screening tests. With 
the combination 'MIS $<5$ and $\mathrm{VF}<20$ ', a high rate of AD patients $(98 \%)$ and a satisfactory rate of MCI patients $(75 \%)$ are detected.

While single-item screening may be applied without any specific requirements, testing with more than one screening tests requires some precautions. In order to prevent interference, it is necessary to begin with the MIS, to fill in some questions about biography or medical history, and then continue with recall before applying other tests in the semantic domain such as BNT or VF. With an inclusion of further tests (LST $<3$, MIS $<5, \mathrm{VF}<20$, and $\mathrm{CDT}>2$ ), sensitivity for $\mathrm{AD}$ and MCI patients can further be improved. This screening procedure should be applied in the following order: LST, MIS learning, CDT, MIS recall, VF, which would take on average less than $10 \mathrm{~min}$. Even with these combinations of screening tests, however, a great overlap remains between patients with $\mathrm{MD}$ and $\mathrm{AD}$. To reliably differentiate the latter, even composite screening measures are insufficient and an extensive testing in a memory clinic is warranted.

\section{Clinical Conclusions}

Differentiation of subjects with MD poses the most difficult challenge for clinical diagnosis, screening tests and even extensive neuropsychological testing. Clinical as well as neuropsychological attempts to differentiate $\mathrm{AD}$ and MD are of limited success [59-61]. Rates of erroneously diagnosing dementia in patients with MD range from 10 to $30 \%$ [62-64]. In the current study with simple screening instruments, patients with MD are similarly impaired on several measures as subjects with $\mathrm{AD}$ and MCI. On the one hand, this is a serious drawback of the screening tests presented here. However, on a symptomatic level, physicians should be aware of cognitive problems in general and memory problems in particular and consider this when obtaining informed consent from the patients or instructing them how to deal with prescriptions or lifestyle changes. Thus, no matter what the cause may be, screening items such as the LST are useful to detect cognitive impairment even for bedside testing. Distinction between MCI subjects and MD subjects may be improved by tests predominantly on the medial temporal lobe such as the MIS, but in the end the differentiation remains insufficient with screening tests and requires further assessment in a specialized institution or may even call for further elaborated methods [19] to be diagnosed accurately.

In summary, single screening measures that may be administered easily and that are applied in about $1 \mathrm{~min}$ provide a fair sensitivity and specificity. Among these single-item screening measures that can be applied in bedside testing or on rounds, the LST and VF are the best. To increase sensitivity and specificity, a combination of tests should be used. With a battery of screening tests whose administration time does not exceed $10 \mathrm{~min}$, all AD patients with MMSE scores of even beyond 23 are recognized as well as a good part of subjects with MCI.

\section{References}

- Callahan CM, Hendrie HC, Tierney WM: Documentation and evaluation of cognitive impairment in elderly primary care patients. Ann Intern Med 1995;122:422-429.

$\checkmark 2$ Erkinjuntti T, Ostbye T, Steenhuis R, Hachinski V: The effect of different diagnostic criteria on the prevalence of dementia. N Engl J Med 1997;337:1667-1674.

3 Bassett SS, Folstein MF: Memory complaint, memory performance, and psychiatric diagnosis: a community study. J Geriatr Psychiatry Neurol 1993;6:105-111.

4 Petersen RC, Smith GE, Waring SC, Ivnik RJ, Tangalos EG, Kokmen E: Mild cognitive impairment: clinical characterization and outcome. Arch Neurol 1999;56:303-308.

$>5$ Burns A, Zaudig M: Mild cognitive impairment in older people. Lancet 2002;360:1963-1965.

6 Lyness JM, Caine ED, King DA, Conwell Y, Duberstein PR, Cox C: Depressive disorders and symptoms in older primary care patients: one-year outcomes. Am J Geriatr Psychiatry 2002; 10:275-282.
-7 O'Boyle M, Amadeo M, Self D: Cognitive complaints in elderly depressed and pseudodemented patients. Psychol Aging 1990;5:467_ 468.

-8 Fischer P: The spectrum of depressive pseudodementia. J Neural Transm Suppl 1996;47: 193-203.

$\checkmark 9$ Nussbaum PD: Pseudodementia: a slow death. Neuropsychol Rev 1994;4:71-90.

10 Zapotoczky HG: Problems of differential diagnosis between depressive pseudodementia and Alzheimer's disease. J Neural Transm Suppl 1998;53:91-95.

11 Berger AK, Fratiglioni L, Forsell Y, Winblad B, Backman L: The occurrence of depressive symptoms in the preclinical phase of AD: a population-based study. Neurology 1999;53: 1998-2002.

12 Kaye JA: Diagnostic challenges in dementia. Neurology 1998;51:S45-S52.

13 Yesavage J: Differential diagnosis between depression and dementia. Am J Med 1993;94: 23S-28S.
14 Valcour VG, Masaki KH, Curb JD, Blanchette PL: The detection of dementia in the primary care setting. Arch Intern Med 2000;160:29642968.

15 Gifford DR, Cummings JL: Evaluating dementia screening tests: methodologic standards to rate their performance. Neurology 1999;52:224-227.

16 Boustani M, Peterson B, Hanson L, Harris R, Lohr KN: Screening for dementia in primary care: a summary of the evidence for the US Preventive Services Task Force. Ann Intern Med 2003;138:927-937.

17 Hyman BT, Van Horsen GW, Damasio AR, Barnes CL: Alzheimer's disease: cell-specific pathology isolates the hippocampal formation. Science 1984;225:1168-1170.

18 Hodges JR: Memory in the dementias; in Tulving E, Craik FIM (eds): The Oxford Handbook of Memory. Oxford, Oxford University Press, 2000, pp 441-459. 
-19 Gron G, Bittner D, Schmitz B, Wunderlich AP, Riepe MW: Subjective memory complaints: objective neural markers in patients with Alzheimer's disease and major depressive disorder. Ann Neurol 2002;51:491-498.

20 Gron G, Riepe MW: Neural basis of the cognitive continuum in episodic memory from health to Alzheimer's disease. Am J Geriatr Psychiatry 2004;12:648-652.

-21 Bittner D, Gron G, Schirrmeister H, Reske S, Riepe MW: $\left[{ }^{18} \mathrm{~F}\right] \mathrm{FDG}-\mathrm{PET}$ in patients with Alzheimer's disease: marker of disease spread. Dement Geriatr Cogn Disord 2005;19:24-30.

-22 Marshall JC, Fink GR: Spatial cognition: where we were and where we are. Neuroimage 2001;14:S2-S7.

$\checkmark 23$ Save E, Poucet B: Hippocampal-parietal cortical interactions in spatial cognition. Hippocampus 2000;10:491-499.

24 Godefroy O, Cabaret M, Petit-Chenal V, Pruvo JP, Rousseaux M: Control functions of the frontal lobes. Modularity of the central-supervisory system? Cortex 1999;35:1-20.

-25 Nagahama Y, Okada T, Katsumi Y, Hayashi T, Yamauchi H, Oyanagi C, Konishi J, Fukuyama $\mathrm{H}$, Shibasaki $\mathrm{H}$ : Dissociable mechanisms of attentional control within the human prefrontal cortex. Cereb Cortex 2001;11:85-92.

-26 Rowe JB, Toni I, Josephs O, Frackowiak RS, Passingham RE: The prefrontal cortex: response selection or maintenance within working memory? Science 2000;288:1656-1660.

-27 Dolan RJ, Bench CJ, Brown RG, Scott LC, Frackowiak RS: Neuropsychological dysfunction in depression: the relationship to regional cerebral blood flow. Psychol Med 1994;24: 849-857.

28 Beats BC, Sahakian BJ, Levy R: Cognitive performance in tests sensitive to frontal lobe dysfunction in the elderly depressed. Psychol Med 1996;26:591-603.

29 Drevets WC: Neuroimaging studies of mood disorders. Biol Psychiatry 2000;48:813-829.

30 Ashford JW, Kolm P, Colliver JA, Bekian C, Hsu LN: Alzheimer patient evaluation and the mini-mental state: item characteristic curve analysis. J Gerontol 1989;44:139-146.

>31 Solomon PR, Hirschoff A, Kelly B, Relin M, Brush M, DeVeaux RD, Pendlebury WW: A 7-minute neurocognitive screening battery highly sensitive to Alzheimer's disease. Arch Neurol 1998;55:349-355.

>32 Hogervorst E, Combrinck M, Lapuerta P, Rue J, Swales K, Budge M: The Hopkins Verbal Learning Test and screening for dementia. Dement Geriatr Cogn Disord 2002;13:13-20.

33 Kuslansky G, Buschke H, Katz M, Sliwinski M, Lipton RB: Screening for Alzheimer's disease: the memory impairment screen versus the conventional three-word memory test. J Am Geriatr Soc 2002;50:1086-1091.

>34 Lipton RB, Katz MJ, Kuslansky G, Sliwinski MJ, Stewart WF, Verghese J, Crystal HA, Buschke H: Screening for dementia by telephone using the memory impairment screen. J Am Geriatr Soc 2003; 51:1382-1390.

\35 Kalbe E, Calabrese P, Schwalen S, Kessler J: The Rapid Dementia Screening Test (RDST): a new economical tool for detecting possible patients with dementia. Dement Geriatr Cogn Disord 2003; 16:193-199.

36 Kalbe E, Kessler J, Calabrese P, Smith R, Passmore AP, Brand M, Bullock R: DemTect: a new, sensitive cognitive screening test to support the diagnosis of mild cognitive impairment and early dementia. Int J Geriatr Psychiatry 2004;19:136-143.

37 Robert PH, Schuck S, Dubois B, Olie JP, Lepine JP, Gallarda T, Goni S, Troy S: Screening for Alzheimer's disease with the short cognitive evaluation battery. Dement Geriatr Cogn Disord 2003; 15:92-98.

38 Zec RF, Landreth ES, Vicari SK, Feldman E, Belman J, Andrise A, Robbs R, Kumar V, Becker R: Alzheimer Disease Assessment Scale: useful for both early detection and staging of dementia of the Alzheimer type. Alzheimer Dis Assoc Disord 1992;6:89-102.

39 Folstein MF, Robins LN, Helzer JE: The MiniMental State Examination. Arch Gen Psychiatry 1983;40:812.

40 Schmand B, Walstra G, Lindeboom J, Teunisse S, Jonker C: Early detection of Alzheimer's disease using the Cambridge Cognitive Examination (CAMCOG). Psychol Med 2000;30:619627.

41 Burkart M, Heun R, Maier W, Benkert O: Dementia screening in routine clinical practice. A comparative analysis of MMSE, SIDAM and ADAS. Nervenarzt 1998;69:983-990.

42 Stuss DT, Meiran N, Guzman DA, Lafleche G, Willmer J: Do long tests yield a more accurate diagnosis of dementia than short tests? A comparison of 5 neuropsychological tests. Arch Neurol 1996;53:1033-1039.

43 McKhann G, Drachman D, Folstein M, Katzman R, Price D, Stadlan EM: Clinical diagnosis of Alzheimer's disease: report of the NINCDS-ADRDA Work Group under the auspices of Department of Health and Human Services Task Force on Alzheimer's Disease. Neurology 1984;34:939-944.

44 Buschke H, Kuslansky G, Katz M, Stewart WF, Sliwinski MJ, Eckholdt HM, Lipton RB: Screening for dementia with the memory impairment screen. Neurology 1999;52:231-238.

45 Leopold NA, Borson AJ: An alphabetical 'WORLD'. A new version of an old test. Neurology 1997;49:1521-1524.

46 Riepe MW, Riss S, Bittner D, Huber R: Screening for cognitive impairment in patients with acute stroke. Dement Geriatr Cogn Disord 2004; 17:49-53.

47 Rosen WG, Mohs RC, Davis KL: A new rating scale for Alzheimer's disease. Am J Psychiatry 1984;141:1356-1364.

48 Lezak M: Neuropsychological Assessment. New York, Oxford University Press, 1995.

49 Shulman KI: Clock-drawing: is it the ideal cognitive screening test? Int J Geriatr Psychiatry 2000; 15:548-561.

50 Lopez OL, Becker JT, Wisniewski S, Saxton J, Kaufer DI, DeKosky ST: Cholinesterase inhibitor treatment alters the natural history of Alzheimer's disease. J Neurol Neurosurg Psychiatry 2002;72:310-314.
51 Geldmacher DS, Provenzano G, McRae T, Mastey V, Ieni JR: Donepezil is associated with delayed nursing home placement in patients with Alzheimer's disease. J Am Geriatr Soc 2003;51:937-944.

52 Kuslansky G, Buschke H, Katz M, Sliwinski M, Lipton RB: Screening for Alzheimer's disease: the memory impairment screen versus the conventional three-word memory test. J Am Geriatr Soc 2002; 50:1086-1091.

53 Pihlajamaki M, Tanila H, Hanninen T, Kononen M, Laakso M, Partanen K, Soininen H, Aronen HJ: Verbal fluency activates the left medial temporal lobe: a functional magnetic resonance imaging study. Ann Neurol 2000; 47:470-476.

54 Okada G, Okamoto Y, Morinobu S, Yamawaki S, Yokota N: Attenuated left prefrontal activation during a verbal fluency task in patients with depression. Neuropsychobiology 2003; 47:21-26.

55 Ravnkilde B, Videbech P, Rosenberg R, Gjedde A, Gade A: Putative tests of frontal lobe function: a PET-study of brain activation during Stroop's Test and verbal fluency. J Clin Exp Neuropsychol 2002;24:534-547.

56 Lin KN, Wang PN, Chen C, Chiu YH, Kuo CC, Chuang YY, Liu HC: The three-item clockdrawing test: a simplified screening test for Alzheimer's disease. Eur Neurol 2003;49:53-58.

57 Powlishta KK, Von Dras DD, Stanford A, Carr DB, Tsering C, Miller JP, Morris JC: The clock drawing test is a poor screen for very mild dementia. Neurology 2002;59:898-903.

58 Ueda H, Kitabayashi Y, Narumoto J, Nakamura K, Kita H, Kishikawa Y, Fukui K: Relationship between clock drawing test performance and regional cerebral blood flow in Alzheimer's disease: a single photon emission computed tomography study. Psychiatry Clin Neurosci 2002;56:25-29.

59 O'Carroll RE, Curran SM, Ross M, Murray C, Riddle W, Moffoot AP, Ebmeier KP, Goodwin GM: The differentiation of major depression from dementia of the Alzheimer type using within-subject neuropsychological discrepancy analysis. Br J Clin Psychol 1994;33(Pt 1):23-32.

60 Gainotti G, Marra C: Some aspects of memory disorders clearly distinguish dementia of the Alzheimer's type from depressive pseudo-dementia. J Clin Exp Neuropsychol 1994;16:6578.

61 Hofman M, Seifritz E, Krauchi K, Hock C, Hampel H, Neugebauer A, Muller-Spahn F: Alzheimer's disease, depression and normal ageing: merit of simple psychomotor and visuospatial tasks. Int J Geriatr Psychiatry 2000; 15:31-39.

62 Smith JS, Kiloh LG: The investigation of dementia: results in 200 consecutive admissions. Lancet 1981;1:824-827.

63 Ron MA, Toone BK, Garralda ME, Lishman WA: Diagnostic accuracy in presenile dementia. Br J Psychiatry 1979;134:161-168.

64 Rabins PV: Reversible dementia and the misdiagnosis of dementia: a review. Hosp Community Psychiatry 1983;34:830-835. 